Published in final edited form as:

Curr Infect Dis Rep. 2009 May ; 11(3): 246-254.

\title{
HIV Infection in the Elderly
}

\author{
Kelly A. Gebo, MD, MPH and Amy Justice, MD, PhD
}

\begin{abstract}
The prevalence of HIV in patients over the age of 50 years is increasing. Although older patients may achieve equal or better virologic suppression at equal rates compared with younger patients, the immunologic bene $3 \mathrm{t}$ of highly active antiretroviral therapy (HAART) in older patients may be reduced compared with younger patients. Comorbidities are more common in older patients than younger patients and can impact management of HIV in these patients. Providers must be cognizant of drug-drug interactions and side effects of HAART regimens when selecting an antiretroviral regimen in older HIV patients. As the HIV-infected population ages, there is a growing need to better determine the ideal HAART regimen and timing of HAART initiation in older patients.
\end{abstract}

\section{Introduction}

Over the past decade, the percentage of all HIV cases in patients 50 years or older increased to more than $17 \%[1 \bullet \bullet$. This increase in the prevalence of HIV in middle-aged and older people is expected to continue over the next decade. Previous data suggested that early in the HIV epidemic, older patients had higher morbidity, mortality, and decreased AIDS-free survival than younger HIV-infected patients [2-4]. This was due to delays in diagnosis and concomitant comorbidities. Since the inception of highly active antiretroviral therapy (HAART), several studies suggested that older patients may not respond as well to HAART as younger patients; particularly, there may be less immune recovery with advancing age [24]. HAART has numerous significant toxicities including dyslipidemia, impaired glucose metabolism, pancreatitis, neuropathy, hepatotoxicity, and lactic acidosis. Older patients may be more likely to develop toxicities than younger patients. In addition, older people are more likely to have comorbidities including cardiovascular disease, renal disease, diabetes, bone loss, and obesity that complicate utilization of antiretroviral therapy. Thus, a balance must be found between the need to treat older individuals earlier to sustain immune function and the potentially greater risk of cumulative toxicity from HAART.

\section{Epidemiology}

Previously, HIV was thought of as a young person's disease; however, due to the increasing prevalence of HIV in middle-aged and older people, the epidemiology of the infected population is changing [5,6]. Although few practitioners would use the age of 50 as a threshold to indicate advanced age, the US Centers for Disease Control and Prevention identi3 ed patients age 50 years or older as a separate age group, because this age group was so much older compared with the lower mean age of HIV patients early in the HIV epidemic [7]. HIV patients are aging because of the increased survival due to HAART, and an

Copyright @ 2009 by Current Medicine Group LLC

Corresponding author: Kelly A. Gebo, MD, MPH, Johns Hopkins University School of Medicine, 1830 East Monument Street, Room 435, Baltimore, MD 21287, USA. kgebo@jhmi.edu.

Disclosure

No potential conflicts of interest relevant to this article were reported. 
increasing number of new HIV infections in older patients due to high-risk exposures [8]. The number of HIV-infected persons older than 65 years has grown tenfold in the past 10 years [5]. It is estimated that by $2015,50 \%$ of people living with HIV/AIDS will be over 50 years of age [9].

There is often a delay to HIV diagnosis in older patients [10]. This may be because physicians are less likely to ask older patients about high-risk behaviors or even suspect HIV in older patients $[5,10]$. In addition, even though older patients may be engaging in high-risk sexual activity, they may be less likely to admit to these behaviors [11]. Older Americans appear to be at increased risk for HIV infection, suggesting a need for HIV prevention efforts targeted at older individuals.

Overall, the prevalence of HIV in older patients has increased in the past decade. Consistent with national trends, a demographic shift has occurred such that these patients mirror the national HIV epidemic, with more infected injection drug users, women, and minorities. Older patients are often diagnosed later than younger patients because physicians are reluctant to ask older patients about high-risk behaviors and patients are unwilling to admit to socially unacceptable behaviors. Future trends in HIV during the next decade are likely to include more primary infections in those over 50 years as well as increasing longevity in those infected at younger ages. With greater longevity, we are also likely to see more longterm complications of HIV infection and treatment.

\section{Clinical, Immunologic, and Virologic Response to HAART}

HAART is effective at reducing HIV viral load and improving CD4 lymphopenia; however, data regarding the clinical, immunologic, and virologic bene $3 \mathrm{t}$ in older patients treated with HAART have been mixed (Table 1). Some authorities have hypothesized that the degree of immune recovery after treatment with HAART may be dependent on the thymus, which loses function with advanced age [12-16]. Data from the early HAART era suggested that age is inversely proportional to how quickly the immune system recovers and that older patients did not respond as well as younger patients [17-19].

There is controversy about the rates of virologic suppression and CD4 response in older compared with younger patients on HAART. Some studies demonstrated a smaller CD4 boost in older patients compared with younger patients treated with HAART [18,20,21], but others have not noted a significant difference in CD4 response between older and younger patients [22-24]. In addition, some studies demonstrated increased virologic suppression in older compared with younger patients [24-27]; another demonstrated better virologic suppression in younger patients [28]; and several demonstrated no difference in virologic suppression between older and younger patients [17,19,23,29].

The largest study to examine the impact of HIV and aging was performed in nearly 50,000 antiretroviral naïve patients in Europe and compared older with younger patients [30••]. The investigators found the probability of virologic response was higher in individuals older than 50 years (possibly due to greater medication adherence), but the probability of immunologic response was lower in individuals 60 years or older. Of note, individuals older than 55 years had poorer clinical outcomes after adjusting for the latest CD4 cell count. This study did not examine differences in response by HAART treatment class.

Only two studies examined the impact of regimen type on clinical outcomes by age. Greenbaum et al. [31] found a significantly decreased time to virologic suppression in older patients on nonnucleoside reverse transcriptase inhibitors (NNRTIs) compared with younger patients on NNRTIs or protease inhibitors (PIs); however, there was no difference in time to virologic suppression in older patients on NNRTIs compared with PIs. On the other hand, 
Patterson et al. [32] found immune reconstitution and viral suppression did not vary by treatment regimen when stratified by age. Both studies had relatively small sample sizes. Future studies that are adequately powered to address the impact of specific antiretroviral therapy regimens are needed to further answer the question of most appropriate treatment type for older patients.

Data regarding the impact of age on HIV progression in the HAART era also demonstrated conflicting results (Table 1). A recent study from Johns Hopkins demonstrated fewer opportunistic infections in older patients than in younger HAART-naïve patients after starting HAART [31]. Other recent studies, however, found that despite higher rates of virologic suppression, older patients have an increased risk of new opportunistic infections compared with younger patients [20,33].

Not surprisingly, most studies found increasing mortality rates in older patients compared with younger patients $[30 \bullet \bullet 31,34]$. Of note, the causes of death in HIV patients treated with HAART have changed from complications of HIV to primarily non-HIV-related causes in American and European cohorts [35].

Overall, these studies have yielded conflicting results regarding clinical outcomes. The previously noted studies are very heterogeneous in study design. Some are cross sectional, others are longitudinal, and many use different outcomes or cutoffs for virologic suppression. In addition, no large trial has evaluated the effect of any one HAART regimen or even class of HAART in regard to outcomes in older compared with younger HIVinfected patients. Therefore, current conclusions regarding HAART therapies in older patients are limited. Larger, controlled trials involving older patients are necessary to evaluate which antiretroviral therapies might be most effective in this population. Until then, current guidelines for HAART regimens should be applied to HIV-infected older patients. Immunologic, virologic, and clinical response should be monitored carefully because recovery may be blunted in older patients.

\section{HAART Metabolism and Toxicity}

With prolonged survival, HIV patients are living long enough to develop comorbidities associated with age and chronic substance use as well as HAART therapies [36]. It is probably no longer appropriate to assume that a new condition (eg, diabetes or liver disease) is due to a single etiology such as HIV infection, HIV treatment, or disease processes completely independent of HIV or its treatment. Instead, it is more useful to consider what may be the contributing causes. For example, although hepatitis $\mathrm{C}$ infection dramatically increases the risk of liver cirrhosis among those with HIV infection, advancing age and HIV infection both increase the risk of cirrhosis among those with hepatitis C.

Unfortunately, most studies of antiretroviral metabolism have excluded patients of advanced age with comorbid disease; therefore, there are few data on the use of antiretrovirals in elderly HIV patients. One study found reduced elimination of zidovudine in elderly patients that resulted in toxic drug levels [37]. Another European study found that age was a risk factor for changes in serum creatinine level in an expanded access study of tenofovir [38].

Treatment with PIs and NNRTIs has been associated with several metabolic disorders, including dyslipidemia. PI regimens have been associated with increased triglycerides, total cholesterol, and low-density lipoprotein (LDL) levels and these metabolic disturbances vary by specific PI. In addition, NNRTIs may increase total cholesterol and LDL levels and induce a concomitant increase in high-density lipoprotein levels. Like PIs, the lipid effects seen with NNRTIs vary by drug used. Lipid abnormalities may be more dangerous in older patients because of increased risk of vascular disease and pancreatitis. 
HIV patients with renal or hepatic insufficiency deserve special attention when certain antiretroviral drugs are used. Renal and hepatic injury are more common among older individuals with HIV, especially among those with prior histories of heavy drug or alcohol use. Tenofovir and indinavir are nephrotoxic and may be more dangerous when used in combination with other drugs, such as lopinavir/ritonavir [39-41]. In addition, tenofovir may be more likely to cause complications in elderly patients, who may have lower creatinine clearance than younger patients. Also, most PIs and NNRTIs can exacerbate hepatic insufficiency in those with preexisting liver disease [42]. Few data exist on administering these drugs in older patients with impaired renal or hepatic clearance. Interactions between different antiretroviral agents are common and have been used to improve activity of some HAART regimens. Few studies have examined the pharmacokinetics of these drugs in the extremes of age, and older patients may be more likely to have drug-drug interactions. Therapeutic drug monitoring may be useful in patients who are at high risk of adverse events.

Pharmacologic interactions between antiretroviral agents and other drugs used in the elderly are common. Proton pump inhibitors are contraindicated with atazanavir and delavirdine due to decreased absorption. Concomitant use of benzodiazepines and protease inhibitors can result in excessive sedation. Allopurinol and ribavirin are also contraindicated with didanosine usage.

There is a need for information about treatment tolerability, drug-drug interactions, shortand long-term toxicity, and interactions with other non-HIV medications in older adults. Most randomized, controlled trials evaluating new antiretroviral drugs or chemoprophylaxis of HIV-related complications excluded patients with advanced age and/or comorbidities. Few studies offered subanalyses comparing outcomes of older patients with younger ones. Older age is associated with a high rate of adverse events from pharmacologic agents; therefore, careful monitoring is required with use of antiretroviral and opportunistic illness prophylaxis medications in older HIV-infected patients. Finally, it will also be important to identify the long-term consequences of HAART therapy as the HIV-infected population ages.

\section{Functional Issues With Aging and HIV}

Frailty is typically defined by decreased physical reserves and is known to increase risk of morbidity and mortality. The frailty phenotype has been defined as the presence of at least three of the following characteristics: exhaustion, slowed walking speed, low activity level, weakness, and weight loss [43,44]. Although Fried et al. [43] found a low prevalence of frailty among HIV-infected individuals in the Multicenter AIDS Cohort Study, they found that frailty occurred earlier among those with HIV compared with HIV-negative controls. Previous studies showed that middle-aged, HIV-infected men on HAART have reductions in exercise capacity, functional performance, physical activity, and grip strength [45]. Frailty is associated with poorer health outcomes than a more robust physical stature $[43,45]$.

The basic mechanisms are not well known; however, it is hypothesized that mitochondrial dysfunction and increased numbers of free radicals and cytokines activate inflammatory pathways. Ultimately this can lead to frailty. Previous studies demonstrated that older people with the frailty phenotype have increased levels of C-reactive protein, D-dimer, factor VIIII, fibrinogen, and interleukin-6 [46]. Increased levels of these markers have also been demonstrated in HIV-infected adults with wasting [47]. 


\section{Comorbidities}

Patients with HIV are now surviving long enough to experience the normal aging process, which includes increased pain, loss of bone and muscle mass, weight loss, decreased glomerular filtration rate, memory loss, and immunosenescence. In addition to chronic HIV infection, older patients also suffer from other medical comorbidities that they previously did not live long enough to endure, including bacterial and viral infections, cancer, and vascular disease. Finally, older people with HIV represent a special population of aging individuals who are predominantly people of color with substantially higher prevalence of past and current substance (alcohol, tobacco, and drug) use and hepatitis $\mathrm{C}$ infection.

Depending on the study, about $60 \%$ of the deaths occurring among those with HIV infection are now attributed to non-AIDS causes [48-50]. That is not to say that these conditions are unassociated with HIV disease or treatment. Many of the most common and serious comorbid conditions-including liver fibrosis/cirrhosis, anemia, renal insufficiency/failure, selected cancers, thrombosis, intracranial hemorrhage, and obstructive lung disease-are more likely to occur among those with HIV infection than among uninfected, demographically similar controls [51-54]. Among those with HIV infection, these conditions are more likely in those with advanced disease. Furthermore, the liver, renal, and bone marrow toxicities associated with antiretroviral treatment are well known and more likely to occur among those with preexisting organ injury [55••]. Instead, we must recognize that chronic HIV infection has become a complex chronic disease in which the etiology of any problem is likely multiple and is often helped, and occasionally exacerbated, by antiretroviral treatment $[55 \bullet \cdot 56]$. As individuals age with HIV infection, organ injury due to HIV infection, aging-related comorbid illnesses, and substance use and abuse will likely lead to even more non-AIDS mortality.

HIV patients are at increased risk of AIDS-related malignancies, particularly Kaposi's sarcoma and non-Hodgkin's lymphoma, and HIV infection is associated with increased risk of cervical cancer and hepatocellular carcinoma due to coinfection with human papilloma virus and hepatitis B and C [57]. Recent studies showed a dramatic increase in overall malignancies and organ-specific malignancies, particularly lung and liver [58-64]. In addition, the risk of certain cancers, particularly lung, breast, colon, and prostate, increase with age [65]. The rates of cancer in HIV patients could dramatically increase over the next 10 years, because HIV is thought to increase susceptibility to malignancy through immune suppression [65]. Recent studies demonstrated higher rates of Hodgkin's lymphoma in HIVinfected patients compared with seronegative controls [66,67]. New studies are needed to evaluate the overall incidence of other carcinomas, as well as AIDS-related malignancies, in HIV-infected older patients. Screening test strategies can be developed for older HIVinfected patients if rates of non-AIDS-related malignancies are higher than expected.

Liver disease is associated with increased hospitalization, morbidity, and mortality in HIV patients [68]. Possible etiologies of liver disease in HIV patients include hepatitis B and C, alcohol use, diabetes, and rapid weight gain. In addition, there is an increased rate of liver toxicity due to multidrug HAART and lipid-lowering agents in HIV patients coinfected with hepatitis. Older patients are more likely to have end-stage liver disease than younger patients either because of a longer course of hepatitis infection or a more rapid course of hepatitis in older patients. End-stage liver disease mortality has increased dramatically in the past 10 years, and hepatitis has become an important predictor of mortality in the HIV-infected population. In addition to the liver disease, patients with liver disease are at increased risk of other complications, including diabetes. A study of US veterans demonstrated increased risk of diabetes in older HIV patients in the HAART era compared with older patients followed in the pre-HAART era. Interestingly, in this study, HIV-hepatitis C coinfection was 
associated with a higher risk of diabetes in the HAART era, but not in the pre-HAART era. Hepatitis C-HIV coinfected patients should be screened for diabetes, especially if they also have risk factors for diabetes (obesity, older age, African American or Hispanic race/ ethnicity).

With advancing age, kidney function declines. Recent estimates demonstrate an increase in the prevalence of chronic renal insufficiency in HIV-infected patients. With the added comorbidities of hypertension and diabetes, which are more common in the minority population, it is reasonable to expect the prevalence of kidney disease in older HIV-infected patients to increase in the next decade. This has significant ramifications for patients and providers because impaired renal function can affect drug clearance and the risk of drug toxicity.

The potential increased risk of cardiovascular disease (CVD) with age is also relevant in HIV patients. Age independently predicts risk for CVD. Although age in itself does not cause CVD, it may reflect the accumulation of atherosclerosis, which predicts the likelihood of suffering a cardiovascular (CV) event [69]. Numerous studies demonstrated an increased risk of vascular events in HIV-infected patients, and several found an association with HAART [70-72]. Others, however, have not found this association and a recent study demonstrated differences in risk of CV events in HIV patients by age group [73-75]. A recent study demonstrated increased rates of hypertension in HIV-infected patients who were HAART-naïve 1 year after starting antiretroviral therapy [76]. HIV providers need to screen carefully for hypertension and treat glucose and lipid abnormalities in HIV-infected patients. It is unknown how much of the increased risk of CV event is a factor of age, HAART use, and/or HIV infection. Therefore, further studies comparing the rates of CVD in HIV-infected older patients to age-matched HIV seronegative controls with similar demographic profiles are needed to examine the overlapping issues of age, HIV infection, and HAART therapy in an older HIV cohort.

Comorbidity, multimorbidity, and toxicity complicate management of the older patient and this is likely to be even more challenging in HIV-infected older patients [77]. Early studies suggested that older people with HIV are at higher risk than age- and race/ethnicity-matched counterparts for liver disease, renal disease, intracerebral hemorrhage, and many forms of cancer [52,77]. It is unknown if HIV-infected older patients on HAART will have higher rates of comorbidities than HIV-infected age-matched controls not on HAAART. HAART therapy may have a synergistic effect with HIV to increase the incidence of comorbidities, and may interact with comorbidities and their treatment. Alternatively, HAART may improve immune function and may reduce the development of certain comorbidities. Understanding the prevalence and incidence of comorbidities and their effect on HIV disease progression is critical in the management of older HIV-infected individuals. Future studies are needed to establish how treatment of comorbidities in HIV patients should be triaged, and if this varies with age. For example, do comorbidities in older HIV patients impact mortality so much that they merit more aggressive surveillance and treatment? How is this best done in conjunction with appropriate HIV treatment? An essential first step is identifying the prevalence and incidence of these comorbidities and their effect on HIV clinical outcomes in older HIV-infected patients.

\section{Conclusions}

The HIV population is aging. Clinicians taking care of older patients should ask all patients about high-risk behaviors and educate them on the risks of HIV. The presentation and natural history of HIV in the older patient may be different than in younger patients with worse immune suppression at diagnosis and more rapid disease progression. Older adults 
have a more severe HIV course, more opportunistic illnesses and malignancies, shortened survival, and shorter AIDS-free intervals than younger patients. In the HAART era, rapid initiation of antiretroviral treatment when indicated is particularly important to reduce HIV disease progression and HIV-associated mortality. Although more rapid HIV progression could occur because of comorbidities in older patients, immunosenescence, and the adverse effects of medications, research is needed to determine the differences in immune reconstitution in older and younger patients.

Current HAART therapy is effective at reducing HIV disease progression and mortality and should be used in older patients. For the older patient, other concomitant drugs used for comorbidities should be explored; nephrotoxic and hepatotoxic drugs should be avoided if possible; and side effects of other drugs, especially in patients with insulin resistance, dyslipidemia, and cardiovascular disease, must be considered when selecting a HAART regimen. Management of comorbidities is complicated and may require triaging conditions by level of importance.

With decreased mortality and an increasing incidence of new infections, it is anticipated that HIV prevalence in older patients will continue to increase in the next decade. HIV in older patients has been relatively ignored until recently, and controlled trials are needed on the therapeutic and clinical outcomes for older HIV-infected patients.

HAART therapy has been effective in reducing morbidity and mortality. However, the clinical improvements may be tempered by the development of resistant HIV and toxicities from antiretroviral therapy, particularly in older patients. Also, the growing number of patients with other comorbidities requiring pharmacologic treatment makes drug-drug interactions far more complicated. Newer classes of antiretroviral drugs in development may help reduce issues of resistance and new coformulations of antiretrovirals may help increase adherence through once-daily treatment options.

The effectiveness of HAART in older patients and factors associated with a more rapid course of HIV infection in patients age 50 and over are unknown. Older adults have more comorbidities than younger patients, and the effect of these comorbidities on HIV progression is unknown. The toxicity from HAART is significant and it is unclear if these toxicities are greater in older patients.

If differences exist in antiretroviral response in older compared with younger patients, this would indicate the need for treatment guidelines specific to older HIV-infected patients. If treatment responses in older patients differ by antiretroviral therapy class, this would affect antiretroviral treatment guidelines for older patients. Similarly, if a drug class has significantly more toxicity in older patients, this class may potentially be avoided in antiretroviral treatment guidelines for older patients. In addition, if differences in immunologic response are identified in older compared with younger patients, this work would be the foundation for future research exploring the differences in T-cell generation and function in older compared with younger HIV-infected patients. Therefore, research to evaluate the impact of age on clinical outcomes and adverse drug events in HIV-infected patients overall and by antiretroviral therapy class is needed, and likely will improve our understanding of the role of age in clinical care of HIV infection.

\section{Acknowledgments}

Supported by the National Institute on Alcohol Abuse and Alcoholism (U10AA013566), the National Institute on Aging (R01 AG026250), and the National Institute on Drug Abuse (K23-DA00523). Dr. Gebo was also supported by the Johns Hopkins University Richard S. Ross Clinician Scientist Award. 


\section{References and Recommended Reading}

Papers of particular interest, published recently, have been highlighted as:

- Of importance

- Of major importance

1•. Centers for Disease Control and Prevention. HIV/AIDS Surveillance Report, 2006. Vol. 18. Atlanta, GA: Centers for Disease Control and Prevention, US Department of Health and Human Services; 2008; Most recent Centers for Disease Control estimates of HIV prevalence and incidence

2. Phillips AN, Lee CA, Elford J, et al. More rapid progression to AIDS in older HIV-infected people: the role of CD4+ T-cell counts. J Acquir Immune Defic Syndr. 1991; 4:970-975. [PubMed: 1679845]

3. Rothenberg R, Woelfel M, Stoneburner R, et al. Survival with the acquired immunodeficiency syndrome. Experience with 5833 cases in New York City. N Engl J Med. 1987; 317:1297-1302. [PubMed: 3500409]

4. Balslev U, Monforte AD, Stergiou G, et al. Influence of age on rates of new AIDS-defining diseases and survival in 6546 AIDS patients. Scand J Infect Dis. 1997; 29:337-343. [PubMed: 9360246]

5. Centers for Disease Control and Prevention. AIDS among persons aged $>$ or $=50$ years-United States, 1991-1996. MMWR Morb Mortal Wkly Rep. 1998; 47:21-27. [PubMed: 9461049]

6. Manfredi R. HIV infection and advanced age: emerging epidemiological, clinical, and management issues. Ageing Res Rev. 2004; 3:31-54. [PubMed: 15164725]

7. Centers for Disease Control and Prevention. 1993 revised classification system for HIV infection and expanded surveillance case definition for AIDS among adolescents and adults. MMWR Recomm Rep. 1992; 41:1-19.

8. Mack KA, Ory MG. AIDS and older Americans at the end of the twentieth century. J Acquir Immune Defic Syndr. 2003; 33(Suppl 2):S68-S75. [PubMed: 12853855]

9. HIV Over Fifty, Exploring the New Threat: Hearings Before the Senate Committee on Aging, (statement of Senator Gordon H. Smith). Washington, DC: 2005.

10. Stall R, Catania J. AIDS risk behaviors among late middle-aged and elderly Americans. The National AIDS Behavioral Surveys. Arch Intern Med. 1994; 154:57-63. [PubMed: 8267490]

11. Ship JA, Wolff A, Selik RM. Epidemiology of acquired immune deficiency syndrome in persons aged 50 years or older. J Acquir Immune Defic Syndr. 1991; 4:84-88. [PubMed: 1984059]

12. Douek DC, McFarland RD, Keiser PH, et al. Changes in thymic function with age and during the treatment of HIV infection. Nature. 1998; 396:690-695. [PubMed: 9872319]

13. Haynes BF, Markert ML, Sempowski GD, et al. The role of the thymus in immune reconstitution in aging, bone marrow transplantation, and HIV-1 infection. Annu Rev Immunol. 2000; 18:529560. [PubMed: 10837068]

14. Mackall CL, Gress RE. Thymic aging and T-cell regeneration. Immunol Rev. 1997; 160:91-102. [PubMed: 9476668]

15. Zhang L, Lewin SR, Markowitz M, et al. Measuring recent thymic emigrants in blood of normal and HIV-1-infected individuals before and after effective therapy. J Exp Med. 1999; 190:725732. [PubMed: 10477556]

16. Jamieson BD, Douek DC, Killian S, et al. Generation of functional thymocytes in the human adult. Immunity. 1999; 10:569-575. [PubMed: 10367902]

17. Manfredi R, Chiodo F. A case-control study of virological and immunological effects of highly active antiretroviral therapy in HIV-infected patients with advanced age. AIDS. 2000; 14:14751477. [PubMed: 10930176]

18. Viard JP, Mocroft A, Chiesi A, et al. Influence of age on CD4 cell recovery in human immunodeficiency virus-infected patients receiving highly active antiretroviral therapy: evidence from the EuroSIDA study. J Infect Dis. 2001; 183:1290-1294. [PubMed: 11262215] 
19. Yamashita TE, Phair JP, Munoz A, et al. Immunologic and virologic response to highly active antiretroviral therapy in the Multicenter AIDS Cohort Study. AIDS. 2001; 15:735-746. [PubMed: 11371688]

20. Grabar S, Kousignian I, Sobel A, et al. Immunologic and clinical responses to highly active antiretroviral therapy over 50 years of age. Results from the French Hospital Database on HIV. AIDS. 2004; 18:2029-2038. [PubMed: 15577624]

21. Kaufmann GR, Furrer H, Ledergerber B, et al. Characteristics, determinants, and clinical relevance of CD4 T cell recovery to $<500$ cells/microL in HIV type 1 -infected individuals receiving potent antiretroviral therapy. Clin Infect Dis. 2005; 41:361-372. [PubMed: 16007534]

22. Cuzin L, Delpierre C, Gerard S, et al. Immunologic and clinical responses to highly active antiretroviral therapy in patients with HIV infection aged > 50 years. Clin Infect Dis. 2007; 45:654-657. [PubMed: 17683004]

23. Tumbarello M, Rabagliati R, De Gaetano Donati K, et al. Older HIV-positive patients in the era of highly active antiretroviral therapy: changing of a scenario. AIDS. 2003; 17:128-131. [PubMed: 12478081]

24. Tumbarello M, Rabagliati R, De Gaetano Donati K, et al. Older age does not influence CD4 cell recovery in HIV-1 infected patients receiving highly active anti retroviral therapy. BMC Infect Dis. 2004; 4:46. [PubMed: 15530169]

25. Bosch RJ, Bennett K, Collier AC, et al. Pretreatment factors associated with 3-year (144-week) virologic and immunologic responses to potent antiretroviral therapy. J Acquir Immune Defic Syndr. 2007; 44:268-277. [PubMed: 17146370]

26. Goodkin K, Shapshak P, Asthana D, et al. Older age and plasma viral load in HIV-1 infection. AIDS. 2004; 18(Suppl 1):S87-S98. [PubMed: 15075503]

27. Knobel H, Guelar A, Valldecillo G, et al. Response to highly active antiretroviral therapy in HIVinfected patients aged 60 years or older after 24 months follow-up. AIDS. 2001; 15:1591-1593. [PubMed: 11505000]

28. Manfredi R, Calza L, Cocchi D, Chiodo F. Antiretroviral treatment and advanced age: epidemiologic, laboratory, and clinical features in the elderly. J Acquir Immune Defic Syndr. 2003; 33:112-114. [PubMed: 12792363]

29. Silverberg MJ, Leyden W, Horberg MA, et al. Older age and the response to and tolerability of antiretroviral therapy. Arch Intern Med. 2007; 167:684-691. [PubMed: 17420427]

30• Collaboration of Observational HIV Epidemiological Research Europe (COHERE) Study Group. Response to combination antiretroviral therapy: variation by age. AIDS. 2008; 22:14631473. Largest study to date of antiretroviral therapy effectiveness by age group. [PubMed: 18614870]

31. Greenbaum A, Wilson LE, Keruly JC, et al. Effect of age and HAART regimen on clinical response in an urban cohort of HIV infected individuals. AIDS. 2008; 22:2331-2339. [PubMed: 18981772]

32. Patterson K, Napravnik S, Eron J, et al. Effects of age and sex on immunological and virological responses to initial highly active antiretroviral therapy. HIV Med. 2007; 8:406-410. [PubMed: 17661850]

33. Anastos K, Barron Y, Cohen MH, et al. The prognostic importance of changes in CD4+ cell count and HIV-1 RNA level in women after initiating highly active antiretroviral therapy. Ann Intern Med. 2004; 140:256-264. [PubMed: 14970148]

34. Grabar S, Weiss L, Costagliola D. HIV infection in older patients in the HAART era. J Antimicrob Chemother. 2006; 57:4-7. [PubMed: 16284223]

35. Smit C, Geskus R, Walker S, et al. Effective therapy has altered the spectrum of cause-specific mortality following HIV seroconversion. AIDS. 2006; 20:741-749. [PubMed: 16514305]

36. McGinnis KA, Fine MJ, Sharma RK, et al. Understanding racial disparities in HIV using data from the Veterans Aging Cohort 3-Site Study and VA administrative data. Am J Public Health. 2003; 93:1728-1733. [PubMed: 14534229]

37. Sauvageone-Matre, H.; Bannie, F.; Tabah, I., et al. Program and Abstracts of the 5th International Conference on AIDS (Montreal). Ottawa: International Development Research Centre; 1989. 
Pharmaco-kinetics of zidovudine in AIDS patients: influence of age and hepatic disorders [abstract MBP 323].

38. Nelson MR, Katlama C, Montaner JS, et al. The safety of tenofovir disoproxil fumarate for the treatment of HIV infection in adults: the first 4 years. AIDS. 2007; 21:1273-1281. [PubMed: 17545703]

39. Tashima KT, Horowitz JD, Rosen S. Indinavir nephropathy. N Engl J Med. 1997; 336:138-140. [PubMed: 8992346]

40. Gallant JE, Parish MA, Keruly JC, Moore RD. Changes in renal function associated with tenofovir disoproxil fumarate treatment, compared with nucleoside reverse-transcriptase inhibitor treatment. Clin Infect Dis. 2005; 40:1194-1198. [PubMed: 15791522]

41. Kiser, J.; Carten, M.; Wolfe, P., et al. Effect of lopinavir/ritonavir on the renal clearance of tenofovir in hiv-infected patients. Presented at the 13th Conference on Retroviruses and Opportunistic Infections; Denver, CO. February 5-8, 2006;

42. Ogedegbe AO, Sulkowski MS. Antiretroviral-associated liver injury. Clin Liver Dis. 2003; 7:475499. [PubMed: 12879995]

43. Fried LP, Tangen CM, Walston J, et al. Frailty in older adults: evidence for a phenotype. J Gerontol A Biol Sci Med Sci. 2001; 56:M146-M156. [PubMed: 11253156]

44. Desquilbet L, Jacobson LP, Fried LP, et al. Multicenter AIDS Cohort Study: HIV-1 infection is associated with an earlier occurrence of a phenotype related to frailty. J Gerontol A Biol Sci Med Sci. 2007; 62:1279-1286. [PubMed: 18000149]

45. Oursler KK, Sorkin JD, Smith BA, Katzel LI. Reduced aerobic capacity and physical functioning in older HIV-infected men. AIDS Res Hum Retroviruses. 2006; 22:1113-1121. [PubMed: 17147498]

46. Leng SX, Yang H, Walston JD. Decreased cell proliferation and altered cytokine production in frail older adults. Aging Clin Exp Res. 2004; 16:249-252. [PubMed: 15462470]

47. Abad LW, Schmitz HR, Parker R, Roubenoff R. Cytokine responses differ by compartment and wasting status in patients with HIV infection and healthy controls. Cytokine. 2002; 18:286-293. [PubMed: 12161104]

48. Lohse N, Hansen ABE, Pedersen G, et al. Survival of persons with and without HIV infection in Denmark, 1995-2005. Ann Intern Med. 2007; 146:87-95. [PubMed: 17227932]

49. Kohli R, Lo Y, Howard AA, et al. Mortality in an urban cohort of HIV-infected and at-risk drug users in the era of highly active antiretroviral therapy. Clin Infect Dis. 2005; 41:864-872. [PubMed: 16107987]

50. Palella FJ, Baker RK, Moorman AC, et al. Mortality in the highly active antiretroviral therapy era: changing causes of death and disease in the HIV outpatient study. J Acquir Immune Defic Syndr. 2006; 43:27-34. [PubMed: 16878047]

51. Justice AC, Lasky E, McGinnis KA, et al. Medical disease and alcohol use among veterans with human immunodeficiency infection: A comparison of disease measurement strategies. Med Care. 2006; 44:S52-S60. [PubMed: 16849969]

52. McGinnis KA, Fultz SL, Skanderson M, et al. Hepatocel-lular carcinoma and non-Hodgkin's lymphoma: the roles of HIV, hepatitis C infection, and alcohol abuse. J Clin Oncol. 2006; 24:5005-5009. [PubMed: 17075119]

53. Fultz SL, McGinnis KA, Skanderson M, et al. Association of venous thromboembolism with human immunodeficiency virus and mortality in veterans. Am J Med. 2004; 116:420-423. [PubMed: 15006592]

54. Crothers K, Butt AA, Gibert CL, et al. Veterans Aging Cohort: Increased COPD among HIVpositive compared to HIV-negative veterans. Chest. 2006; 130:1326-1333. [PubMed: 17099007]

55 •. DHHS Panel on Antiretroviral Guidelines for Adults and Adolescents: Guidelines for the Use of Antiretroviral Agents in HIV-Infected Adults and Adolescents; 2006. Washington, DC: Department of Health and Human Services/Henry J. Kaiser Family Foundation; 2008. Most recent treatment guidelines for HIV-infected adults and adolescents

56. El-Sadr WM, Lundgren JD, Neaton JD, et al. Strategies for Management of Antiretroviral Therapy (SMART) Study Group. CD4+ count-guided interruption of antiretroviral treatment. N Engl J Med. 2006; 355:2283-2296. [PubMed: 17135583] 
57. Frisch M, Biggar RJ, Engels EA, et al. AIDS-Cancer Match Registry Study Group: Association of cancer with AIDS-related immunosuppression in adults. JAMA. 2001; 285:1736-1745. [PubMed: $11277828]$

58. Biggar RJ, Kirby KA, Atkinson JH, et al. AIDS-Cancer Match Registry Study Group: Cancer risk in elderly persons with HIV/AIDS. J Acquir Immune Defic Syndr. 2004; 36:861-868. [PubMed: 15213571]

59. Long JL, Engels EA, Moore RD, Gebo KA. Incidence and outcomes of malignancy in the HAART era in an urban cohort of HIV-infected individuals. AIDS. 2008; 22:489-496. [PubMed: 18301061]

60. Kirk GD, Merlo C, O'Driscoll P, et al. HIV infection is associated with an increased risk for lung cancer, independent of smoking. Clin Infect Dis. 2007; 45:103-110. [PubMed: 17554710]

61. Allardice GM, Hole DJ, Brewster DH, et al. Incidence of malignant neoplasms among HIVinfected persons in Scotland. Br J Cancer. 2003; 89:505-507. [PubMed: 12888821]

62. Bower M, Powles T, Nelson M, et al. HIV-related lung cancer in the era of highly active antiretroviral therapy. AIDS. 2003; 17:371-375. [PubMed: 12556691]

63. Chaturvedi AK, Pfeiffer RM, Chang L, et al. Elevated risk of lung cancer among people with AIDS. AIDS. 2007; 21:207-213. [PubMed: 17197812]

64. Engels EA, Brock MV, Chen J, et al. Elevated incidence of lung cancer among HIV-infected individuals. J Clin Oncol. 2006; 24:1383-1388. [PubMed: 16549832]

65. Engels EA. Human immunodeficiency virus infection, aging, and cancer. J Clin Epidemiol. 2001; 54:S29-S34. [PubMed: 11750207]

66. Herida M, Mary-Krause M, Kaphan R, et al. Incidence of non-AIDS-defining cancers before and during the highly active antiretroviral therapy era in a cohort of human immunodeficiency virusinfected patients. J Clin Oncol. 2003; 21:3447-3453. [PubMed: 12972519]

67. Clifford GM, Polesel J, Rickenbach M, et al. Swiss HIV Cohort Study: Cancer risk in the Swiss HIV cohort study: associations with immunodeficiency, smoking, and highly active antiretroviral therapy. J Natl Cancer Inst. 2005; 97:425-432. [PubMed: 15770006]

68. Gebo KA, Diener-West M, Moore RD. Hospitalization rates differ by hepatitis C status in an urban HIV cohort. J Acquir Immune Defic Syndr. 2003; 34:165-173. [PubMed: 14526205]

69. Smith SC Jr, Jackson R, Pearson TA, et al. Principles for national and regional guidelines on cardiovascular disease prevention: a scientific statement from the World Heart and Stroke Forum. Circulation. 2004; 109:3112-3121. [PubMed: 15226228]

70. Holmberg SD, Moorman AC, Williamson JM, et al. Protease inhibitors and cardiovascular outcomes in patients with HIV-1. Lancet. 2002; 360:1747-1748. [PubMed: 12480430]

71. Klein D, Hurley LB, Quesenberry CP, Sidney S. Do protease inhibitors increase the risk for coronary heart disease in patients with HIV-1 infection? J Acquir Immune Def c Syndr. 2002; 30:471-477.

72. Holmberg SD, Moorman AC, Greenberg AE, et al. DAD Steering Committee: Trends in rates of myocardial infarction among patients with HIV. N Engl J Med. 2004; 350:730-732. [PubMed: 14960752]

73. Coplan PM, Nikas A, Japour A, et al. Incidence of myocardial infarction in randomized clinical trials of protease inhibitor-based antiretroviral therapy: an analysis of four different protease inhibitors. AIDS Res Hum Retroviruses. 2003; 19:449-455. [PubMed: 12882653]

74. Bozzette SA, Ake CF, Tam HK, et al. Cardiovascular and cerebrovascular events in patients treated for human immunodeficiency virus infection. N Engl J Med. 2003; 348:702. [PubMed: 12594314]

75. Currier JS, Taylor A, Boyd F, et al. Coronary heart disease in HIV-infected individuals. J Acquir Immune De3 c Syndr. 2003; 33:506-512.

76. Palacios R, Santos J, Garcia A, et al. Impact of highly active antiretroviral therapy on blood pressure in HIV-infected patients. A prospective study in a cohort of naive patients. HIV Med. 2006; 7:10-15. [PubMed: 16313287]

77. Goulet JL, Fultz SL, Rimland D, et al. Aging and infectious diseases: do patterns of comorbidity vary by HIV status, age, and HIV severity? Clin Infect Dis. 2007; 45:1593-1601. [PubMed: 18190322] 


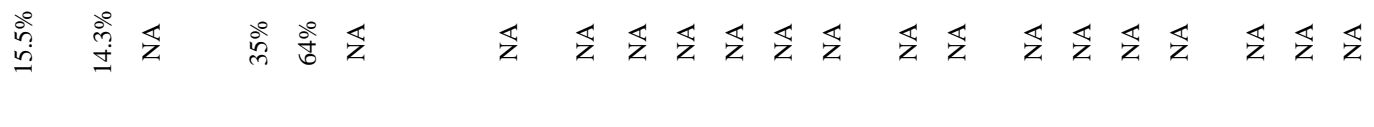

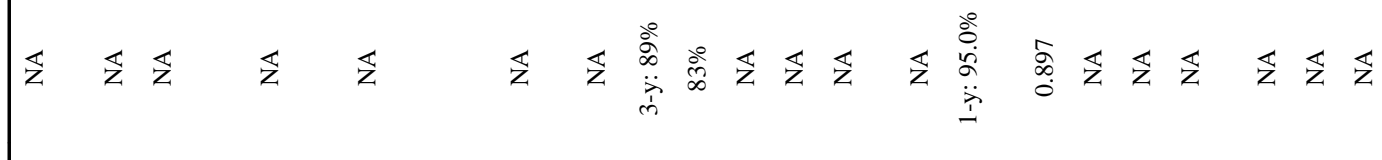

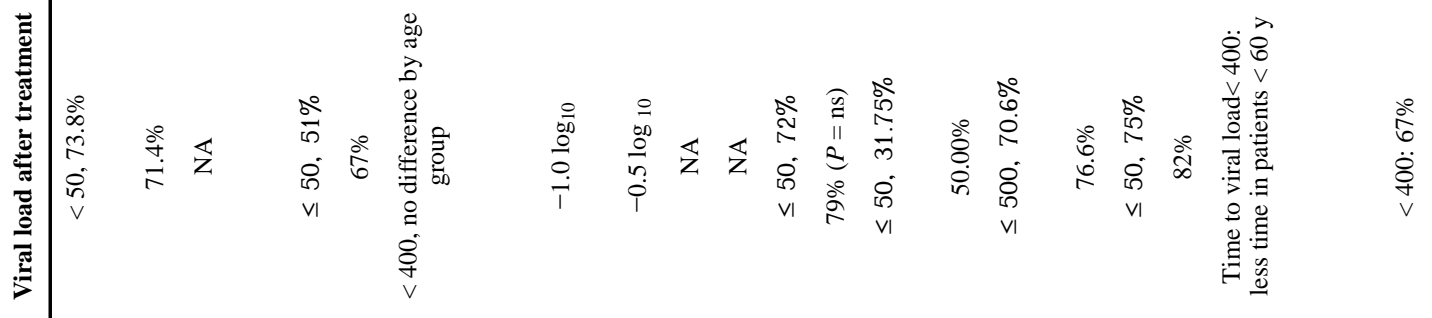

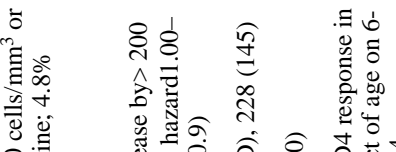

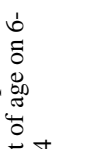

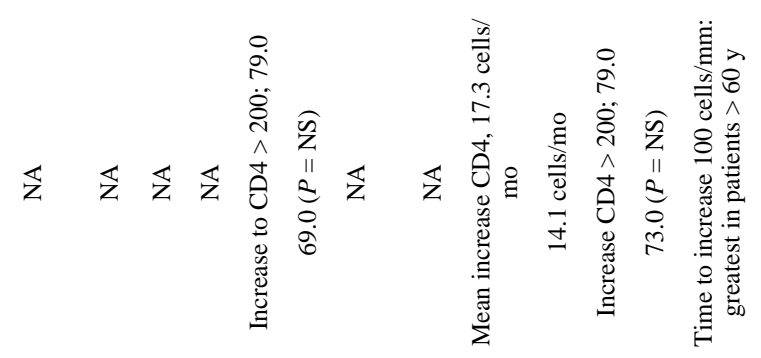

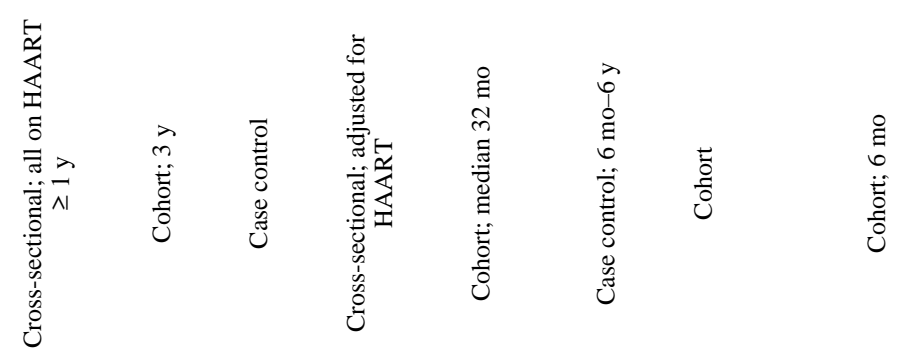




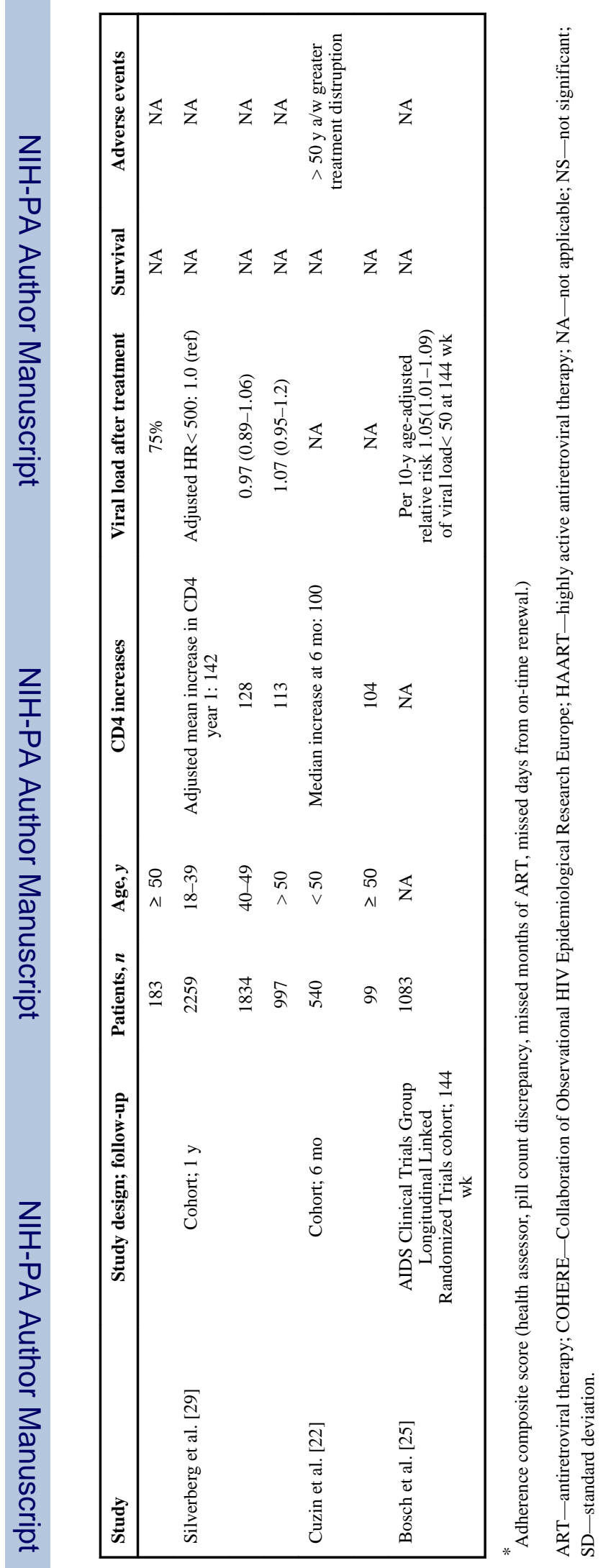

Curr Infect Dis Rep. Author manuscript; available in PMC 2011 July 5. 